\title{
Assessment of the contact eye cover as an effective method of restricting visual input
}

\author{
DANIEL M. LEVINSON and CHARLES L. SHERIDAN \\ University of Missouri and Veterans Administration Hospital, Kansas City, Missouri 64110 \\ TERRY J. HOTTMAN \\ University of California, Santa Barbara, California 93106 \\ DON R. JUSTESEN \\ Neuropsychology Laboratories, Veterans Administration Hospital, Kansas City, Missouri 64110
}

DONNELL J. CREEL

Neuropsychology Laboratories, Veterans Administration Hospital, Salt Lake City, Utah 84132

and

\author{
ROBERT E. SANDERS \\ University of Missouri, Kansas City, Missouri 64110
}

\begin{abstract}
In the wake of several studies that have cast doubt upon the effectiveness of contact eye covers in restricting vision, we performed a series of five experiments to the end of achieving reversible blinding of the albino rat. The data of Experiment 1 indicated that the contact eye cover can be as effective as a rubber cup in restricting visual input. In Experiment 2, animals that were fitted binocularly with opaque eye covers performed as if blind on a task involving acquisition of pattern discrimination. In Experiment 3, binocular coverage with the opaque eye cover resulted in chance performance across 300 trials of a previously acquired pattern-discrimination habit. In Experiment 4, the base diameter of the eye cover was found to be a critical factor: Performance of a previously acquired brightness discrimination was reduced to chance levels by contact eye covers that approximated $7.0 \mathrm{~mm}$ in diameter. In Experiment 5, a smaller eye cover (6-mm diam) had no effect in limiting the visually evoked electrocortical response of the albino rat, while an eye cover of $7.2-\mathrm{mm}$ diam produced a reliable attenuation of the response. The collective results indicate that appropriately fabricated contact eye covers are a viable means of restricting visual input and may justifiably be considered contact occluders.
\end{abstract}

At first glance, the problem of reversible restriction of visual input (blinding) may seem trivial, since the obvious solution appears to consist either in placing the subjects in a darkened room or in covering their eyes with a blindfold. However, the darkened room cannot be used for monocular blinding and may limit the experimenter as much as his subject. Blindfolding is often the technique of choice with human subjects, but certain animals are not well suited to the secure fitting of a blindfold; further, the blindfold is unreliable, even when used on human beings. Many professional magicians have performed visually guided tasks even

We express our gratitude to Linda Mann for her assistance and patience in preparing the manuscript. We also wish to thank Norman Dunsmore, Serena Tollefson, and Lawrence Midaugh for assistance in gathering portions of the data reported in Experiment 2. Requests for reprints should be sent to Daniel $M$. Levinson, Department of Psychology, C-B Annex, University of Missouri-Kansas City, 5100 Rockhill Road, Kansas City, Missouri 64110. when encumbered by the most elaborate of blindfolds (Gibson, 1974). Despite the potential for "peeking," several investigators have used eye patches (e.g., Bergum \& Flamm, 1975; Herman, Tauber, \& Roffwarg, 1974; Zubek \& Bross, 1972) or opaque pads (Procopis \& Jameson, 1974) on human subjects. The effectiveness of these devices has been assumed, but results of stringent tests have not been reported.

The animal subject may be greatly disturbed by an eye patch or by the procedure involved in installing it. Such eye covers may also induce undesirable changes in the animals' behavior. Muntz and Sutherland (1964) reported that the unilateral eye patch tends to produce positional responding in rats. Depending on the shape of the animal's head and the degree of vigor with which it resists wearing the blinder, mild to severe difficulty may be incurred in working with reversibly blinded animals.

A variety of devices has been used for reversible blinding. Myers (1955) used a soft, rubber monocular 
mask to restrict vision in cats; a similar method was used by Sperry (1961) in studying interocular transfer in split-brain monkeys. Other types of eye covers include rubber cups with chicks (Horn, Rose, \& Bateson, 1973), band-aids or goggles with pigeons (cf. Cheney \& Tam, 1972; Corballis \& Luther, 1973; Tieman, Tieman, Brady, \& Hamilton, 1974), a textile mask with rabbits (van Hof \& Lagers-van Haselen, 1975), an eye patch sutured over the eye with kittens (Cornwell, 1974), and corneal contact lenses with cats (Hranchuk \& Webster, 1975).

In general, investigators have done little to assure that the method of blinding animals is fully effective. If the device renders the eye invisible to the experimenter and fits snugly over the animal's eye, it is usually assumed to be effective. That this may be a dangerous assumption was shown in experiments on a particularly elegant method of covering the eyes devised by Shuck and Coppola (1963). They developed a floating contact eye cover that resembles a contact lens but is made of opaque vinyl acrylic. Eye covers based on their design have been used extensively in studies of rats (Boles \& Sheridan, 1969; Creel \& Sheridan, 1966; Levinson, Hottman, \& Sheridan, 1971; Levinson \& Sheridan, 1967a; Levinson \& Sheridan, 1969; Sheridan, 1965; Sheridan \& Shrout, 1966) and guinea pigs (Levinson, 1972; Levinson, Riffle, Reeves, \& Sheridan, 1977; Levinson \& Sheridan, 1967b; Lynch \& Sheridan, 1970; Petre \& Sheridan, 1966; Riffle, Reeves, \& Levinson, 1976).

Sheridan and Shrout (1965) found that binocularly covered animals performed reliably above chance levels on a black-white discrimination following measures of monocular acquisition and interocular transfer. This finding was of particular interest since they used a modified eye cover based on the device of Shuck and Copolla (1963), a device that has been used in virtually all of the cited experiments on interocular transfer in rodents. Sheridan and Shrout (1965) warned that careful controls should be used to assure occlusion when using this method. Their admonition applies equally well to the other types of blinders.

Subsequent to the investigations of Sheridan and Shrout (1965), results of testing for "peeking" through the use of binocular contact eye coverage at completion of experiments have generally been reported. The tests have usually involved pattern discriminations rather than the black-white discriminations with which Sheridan and Shrout (1965) observed leakage. Generally, performance of a pattern discrimination drops to chance levels after binocular coverage. However, Chorover and Chase (1968) observed binocularly covered rats over a large number of trials and found evidence of the animal's ability to discriminate patterns at high levels of accuracy. Chorover and Chase concluded that studies of interocular transfer based on contact eye covers were invalid. We disagree with this conclusion, since tests of performance with binocular coverage that are made immediately after measures of interocular transfer are probably a more accurate reflection of the animal's visual competence during the experiment than is a test of what it eventually learns after hundreds of trials while binocularly covered. Further, remarkably small levels of transfer have been observed in rats tested for interocular transfer while wearing a contact eye cover, as compared with levels reported in higher species. The values of these transfer levels would presumably be even smaller than the apparent values, if leakage indeed occurs during interocular testing. Nevertheless, the findings of Chorover and Chase (1968) and of Sheridan and Shrout (1965) indicate that methods of reversible blinding should be meticulously evaluated. It is imperative that conditions under which contact eye coverage is effective be identified and that alternative methods be sought for those situations in which it is not effective. A series of studies was performed with these ends in mind.

\section{Manufacture of the Contact Eye Cover}

The eye covers used in our studies are similar to contact lenses, but are shaped to cover an animal's eye to the base. The eye cover for rats is made by holding a small square $\left(2 \mathrm{~cm}^{2}\right)$ of $.25-\mathrm{mm}$ acrylic sheet in a small pair of hemostats and heating it over a Bunsen burner until it is malleable, then pressing it over a ball bearing (typically $6 \mathrm{~mm}$ in diameter, which approximates the size of the adult rat's eye) with a length of flared copper tubing (I.D. $=9 \mathrm{~mm}$ ). The piece of acrylic, when cooled to ambient temperature, is trimmed to form a truncated hemisphere. Any rough or jagged edges along the base are then removed with fine sandpaper and emery cloth. The resulting appliance (Figure 1) typically has a depth of $3.5 \pm .2 \mathrm{~mm}$ and a base diameter of $7.0 \pm .2 \mathrm{~mm}$. Eye covers for guinea pigs are similarly manufactured, except that the ball

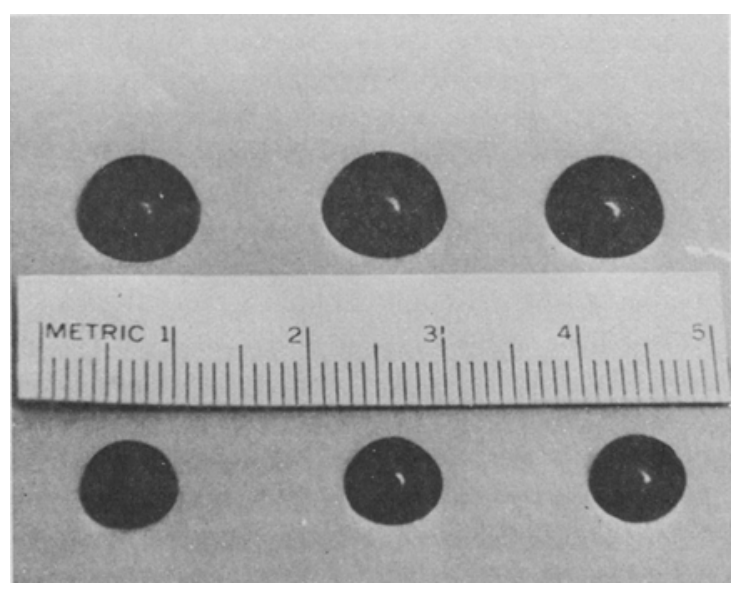

Figure 1. Eye covers for use with rats (below) and guinea pigs (above). 
bearing is usually $8 \mathrm{~mm}$ in diameter and the length of copper tubing with which the acrylic is pressed has an I.D. of approximately $1 \mathrm{~cm}$. The guinea pig's eye cover (Figure 1) has a depth near $3.7 \mathrm{~mm}$ and a base diameter of approximately $9.0 \mathrm{~mm}$. Dimensions are sometimes varied in order to fit the cover to animals of differing ocular mass.

\section{Insertion and Removal of the Contact Eye Cover}

Prior to covering an animal's eye, several eye covers are placed on a clean dry surface. A cover is then filled with a contact lens wetting solution, such as that manufactured by Barnes and Hind (Sunnyvale, California). The cover is then inverted and placed on the animal's eye. The animal, which is wrapped fairly tightly in a towel with its head protruding, is held in one hand, and the thumb and forefinger of that hand are used to part the animal's eyelids. Using the forefinger of the other hand, an eye cover is picked up after pressing the pad of the finger on the top of the cover. The cover is then placed on the animal's eye, with a minimum of pressure; the procedure is similar to that used to apply contact lenses to the human eye. The appliance should cover the eye to the base, and the eyelid should be free to close. Animals often wipe the covered eye with their paws immediately following insertion. Such wiping probably reflects initial discomfort from tactile or hypothermal stimulation, but the discomfort appears to be transitory. Photographs of $a \cdot$ rat and of a guinea pig fitted with eye covers are presented in Figure 2.

To remove an eye cover, the animal is first wrapped in a towel. After its eyelids are parted, the rubber tip of a gingival massager (e.g., that on the Pycopay toothbrush) is inserted under the edge of the cover, which is then lifted out. Eye covers should always be removed at the end of a session of training or testing, since damage to an animal's eye may otherwise result (Shuck \& Coppola, 1963).

\section{EXPERIMENT 1a}

If an albino rat can make a visual discrimination while binocularly covered, it is reasonable to assume that leakage of information to a covered eye in studies of interocular transfer (i.e, under conditions of monocular coverage) could result in an overestimation of interocular transfer. Our first experiment was designed to compare a new type of appliance against the contact eye cover with respect to the amount of interocular transfer that occurred after rats acquired a black-white discrimination. The experiment also assessed the effects of unilateral enucleation in conjunction with monocular coverage.

\section{Method}

Subjects. The subjects were four adult male albino rats of the Sprague-Dawley strain. They weighed approximately $450 \mathrm{~g}$ at the onset of the study.
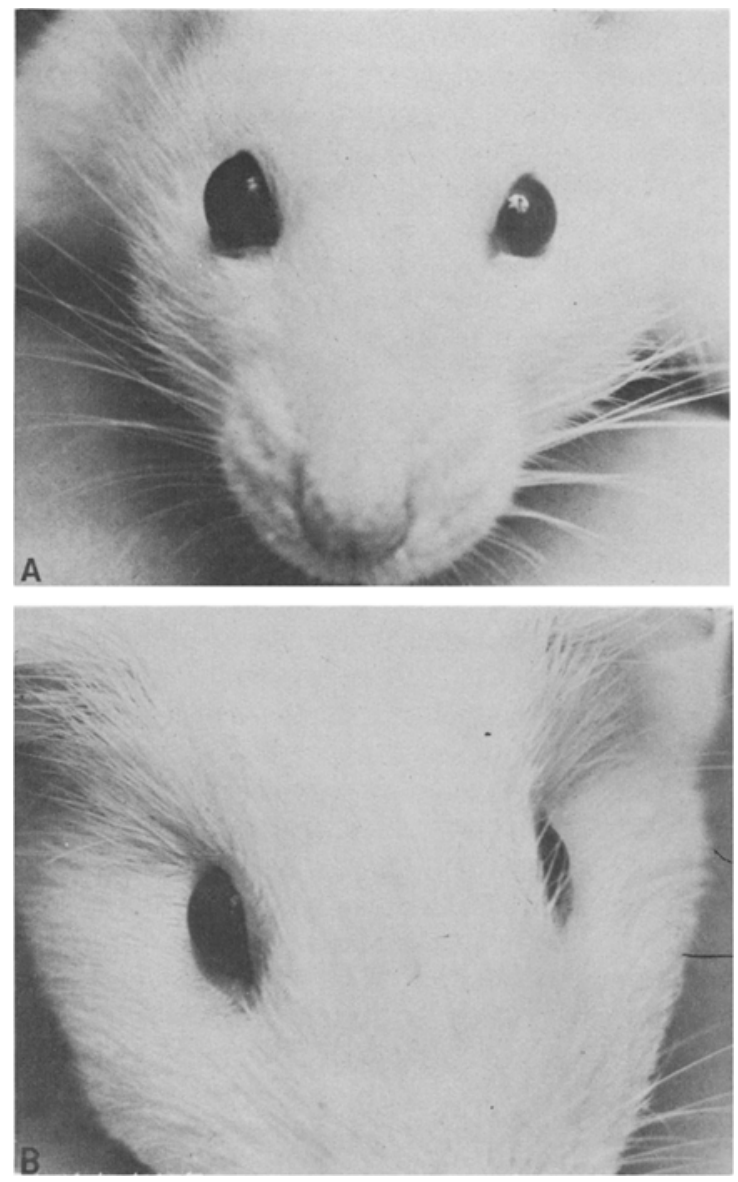

Figure 2. Photographs of a rat (a) and guinea pig (b) wearing contact eye covers on their right eyes.

Apparatus and Procedure. A two-choice discriminative apparatus was used that was similar to the one employed by Thompson and Bryant (1955). It consisted of a startbox and runway (separated by a guillotine door) with two alternative entryways and a goalbox. Motivational shock (high-voltage, high-resistance constant-current generator set at 1-3 mA) was provided in the startbox, runway, and entryway areas via four independently electrifiable sets of grids. A controllable light source insured constant illumination of the stimulus doors of $2.3 \mathrm{~lx}$, as measured by a General Electric light meter (Type 213). The stimulus doors were of black and white Plexiglas sheets, with respective reflectances near $80 \%$ and $10 \%$. A desk bell was used to sound a warning signal; ambient sound was masked by a noise generator (Lafayette Instrument Company, Model 1431). The appliance to be tested and compared with the contact eye cover consisted of a rubber suction cup approximately $16 \mathrm{~mm}$ in diameter that was affixed with rubber cement to one end of a $2 \times 3 \mathrm{~cm}$ strip of metal tape. There were two holes drilled at the other end of the metal tape, which was fastened to two small bolts chronically anchored to the animal's skull. Nuts secured the metal tape to the animal's head. Cortical anchor screws were dipped in Eastman 910 adhesive before attachment to the skull. Dental acrylic was then poured on the skull and around the anchoring screws; the two bolts, each approximately $3 \mathrm{~mm}$ in diameter and $10 \mathrm{~mm}$ long, were set into the acrylic before it hardened. The metal tape was shaped to fit the curvature of the rat's head, so that when the appliance was bolted to an animal, the cup fit flush with the side of the head and completely covered the eye. An animal 


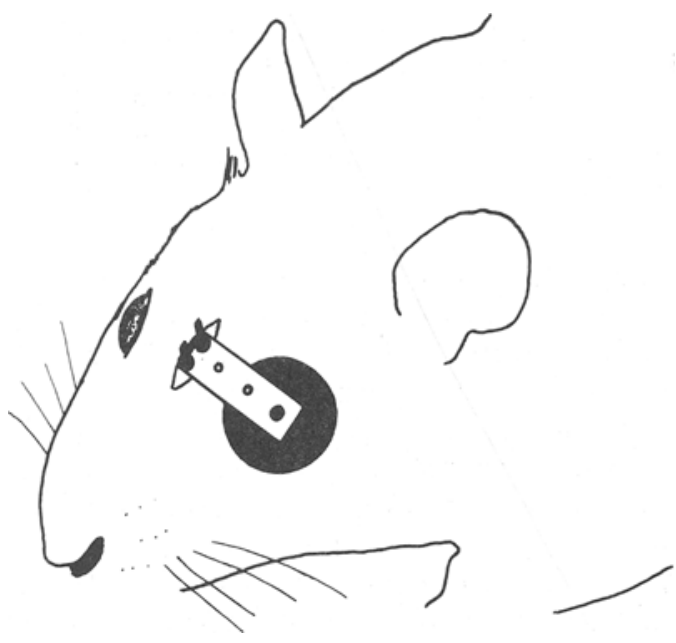

Figure 3. Semischematic illustration of a rat wearing a rubber cup appliance.

wearing such an appliance is schematically illustrated in Figure 3.

Before its eye was covered, each animal was pretrained to avoid shock. On Day 1, an animal was placed in the apparatus for $30 \mathrm{~min}$ to permit exploration; from Day 2 on, the animals received trials in escape-avoidance learning. If an animal did not leave the start area within $10 \mathrm{sec}$, the area was electrified until the animal moved into the runway area; if the animal did not move into the goalbox within $20 \mathrm{sec}$ after the lowering of the guillotine door, the runway area was electrified. After avoiding shock by running from start- to goalbox (with no doors in place) during three consecutive trials, each rat was trained to knock down gray doors that first partially, and later fully, blocked the goal area from the animal's view. During this phase of pretraining, both doors were unlocked and neither entryway grid was electrified. Each rat was trained until it avoided shock five consecutive times when both gray doors were initially in a fully closed but unlocked position.

Upon commencement of discrimination training, the cue doors were fully closed; the incorrect door was locked and the grid before it was electrified. Any contact with the incorrect entryway grid was scored as an error. The position of the correct cue door was varied across trials in a sequence described by Fellows (1967). Each animal was fitted with the cup appliance and trained 25 trials/day until an $18 / 20$ criterion was met (i.e., a criterion of 18 correct responses in 20 consecutive trials); it was then overtrained to a $9 / 10$ criterion. The eye cover was subsequently shifted to the opposite eye and the animal was tested for interocular transfer by being retrained to the $18 / 20$ criterion. Laterality of eye coverage and designation of cue correctness were counterbalanced.

After each animal again met the $18 / 20$ criterion, one eye was enucleated and the other was covered with a cup appliance. The rats performed during 200-270 trials and then were alternately given 20 trials with and 20 trials without eye coverage, for a total of 40 trials/day over a period of 4-6 days. During acquisition, odor cues were controlled.

Next, the cup appliance was removed and a contact eye cover was placed upon the remaining eye of each animal. The animals were again overtrained. If criterion was met within 200 trials, the contact eye cover was removed, the cup appliance was replaced, and the rat was given a final block of 20 trials. At completion of the experiment, brains were removed and examined for damage. Gross examination revealed the presence of small frontal lesions in two animals, one of which also had a small lesion of the striate cortex. All lesions appeared to be due to the cortical screws and were less than $1 \mathrm{~mm}$ deep.

\section{Results and Discussion}

All four animals showed a high degree of interocular transfer: The median of savings was $83 \%$. Measures of performance during the phase of the study in which cup eye coverage was alternated with no eye coverage are shown in Table 1. With coverage, performance was at chance levels; without it, the animals showed near perfect retention of the discrimination. Under conditions of contact eye coverage, all animals met criterion within 160 trials. When the animals were retested wearing the cup appliance, they performed at chance levels.

In two studies in which contact eye covers were used during measures of interocular transfer of a black-white discrimination in the albino rat, Sheridan (1965) and Sheridan and Shrout (1965), respectively, obtained median interocular savings scores of $89.8 \%$ and $75.9 \%$. These values bridge the savings score observed by us in rats with the rubber-cup appliance (83\%), which indicates that the earlier measures of transfer were not heavily influenced by leakage of visual input.

\section{EXPERIMENT 1b}

The cup appliance was superior to the contact eye cover, but required elaborate procedures for attachment and entailed neural damage. In the two subsequent experiments, we tried to improve the method of fixing the cup appliances to the skull, and also evaluated the effectiveness of the eye cups under more demanding circumstances.

\section{Method}

Subjects. The subjects were 10 male Sprague-Dawley albino rats weighing approximately $250 \mathrm{~g}$ each.

Apparatus. The apparatus described in Experiment 1a was slightly modified. The stimulus doors contained slots into which a piece of clear glass that covered the cue card was placed. Contact by an animal with a door was restricted to the glass cover, thus preventing the use of odor cues as a basis of discrimination. Further, the stimulus doors were hinged at the side and swung open into the goalbox when pushed upon.

Procedure. After each of 10 animals was anesthetized with sodium pentobarbital, one eye was removed; laterality of enucleation was counterbalanced. Bolts were then mounted on the skulls of five animals. The jeweller's screws were placed close together along the anterolateral margin of the frontal bone, well removed from the frontal poles of the brain. Instead of using jeweller's screws, we strung wire through the bony ridge above the eye sockets; the bolts were further secured by placing dental acrylic around their base.

Table 1

Experiment 1a: Mean and Median Percentage of Correct Responses Under Alternating Conditions

\begin{tabular}{cccccc}
\hline & \multicolumn{2}{c}{ Cup Coverage } & & \multicolumn{2}{c}{ No Coverage } \\
\cline { 2 - 3 } \cline { 5 - 6 } Subject & Mean & Median & & Mean & Median \\
\hline 1 & 41.0 & 40 & 96.0 & 100 \\
2 & 47.5 & 50 & & 87.5 & 100 \\
3 & 46.5 & 50 & & 97.5 & 100 \\
4 & 47.8 & 50 & 95.6 & 100 \\
\hline
\end{tabular}


After recovery from surgery, each animal was pretrained to go through doors that did not contain stimulus cards. The animals were then given 25 training trials/day on a black-white discrimination until they reached a $20 / 25$ criterion of correct responding during 2 consecutive days followed by a $23 / 25$ criterion on a third day. Then each animal underwent either cup or contact coverage of the remaining eye and was given 300 additional trials. As a test for retention of the discriminative habit, a block of 25 trials with no eye coverage followed each 100-trial block with eye coverage.

\section{Results and Discussion}

Although all animals performed the discrimination at the conclusion of the study, none performed above chance levels when both eyes were covered, even during the course of 300 trials, while wearing either the cup appliance or contact eye covers. That rats with contact eye covers did not respond better than chance for over 300 trials on a black-white discrimination is at variance with the findings of Experiment 1a, as well as with those of Chorover and Chase (1968) and Sheridan and Shrout (1965). It seems unlikely that the discrepancy is due to the differing modes of retricting visual input employed in the experiments (i.e., binocular contact coverage as opposed to monocular contact coverage coupled with unilateral enucleation). We believe the contact eye covers were large enough to restrict the vision of the smaller rats used in Experiment lb.

\section{EXPERIMENT 1c}

The reliability of the cup appliance was further evaluated by measuring its effectiveness in blocking the discrimination of light-dark cues under two differing conditions.

\section{Method}

Subjects. Ten adult male albino rats of the Sprague-Dawley strain weighing $250 \mathrm{~g}$ each were used as subjects. Five animals were assigned to a shuttle task; the other five were trained in a Thompson-Bryant apparatus.

Apparatus. The shuttlebox consisted of two chambers separated by a guillotine door. The chamber floors consisted of electrifiable grids. Motivational shock was provided by the shock generator described in Experiment 1a. Each chamber contained a 7.5-W light bulb, the illumination of which served as a discriminative stimulus. Intensity of illumination was controlled via a variable transformer. We used a Thompson-Bryant apparatus that was similar to that described in Experiment 1b, except that a 7.5-W light bulb (also illuminated by a variable transformer) was placed behind each glass entryway.

Procedure. Bolts were anchored to the skull of each animal as described in Experiment 1b. The animals also underwent unilateral enucleation, with counterbalancing of laterality. Following recovery from surgery, the five animals assigned to the shuttle task were trained to avoid the dark and to enter the lighted chamber. If an animal either entered the dark chamber, or failed to shuttle within $5 \mathrm{sec}$ after the previously illuminated chamber was darkened, an error was scored for that trial. A random series of 15-, 30-, and 40-sec intertrial intervals was incorporated to preclude temporal cuing. The five animals assigned to the Thompson-Bryant apparatus were trained to enter the goalbox through the lighted door. During any trial that an animal contacted the unlighted door or was shocked by the corresponding entryway grid, an error was recorded. After each of the 10 animals had been highly trained to perform its respective discriminative task, a cup appliance was attached to its head and its ability to perform the task while wearing the appliance was assessed.

\section{Results and Discussion}

Of the five animals trained on the shuttle task, two responded correctly during more than $90 \%$ of the trials while wearing the cup appliance. When the light stimulus was not presented, neither animal performed better than chance. The three animals that did not correctly shuttle with the eye covered did not return to baseline performance upon removal of the appliance.

Two of the five animals trained in the ThompsonBryant apparatus performed the light-dark discrimination with the remaining eye covered; they continued to perform successfully even when the 7.5-W $125-\mathrm{V}$ light bulb was excited by only $35 \mathrm{~V}$ rms. When the differential illumination of the entryway doors was removed, the animals no longer performed the discrimination. The three animals that could not perform the task while wearing the cup appliance did discriminate between the light-dark cues when the appliances were removed.

\section{GENERAL DISCUSSION, EXPERIMENT 1}

Taken collectively, the results of Experiment 1 indicate that there are circumstances in which both cup and contact eye covers are effective in preventing discrimination of black and white stimuli. These data aiso indicate that there are other circumstances in which the animals can learn a black-white discrimination even when binocularly covered, but that the ability to acquire a discrimination under these conditions has no noteworthy effect on estimates of interocular transfer. Further, the results indicate that there are circumstances under which a light-dark task can be performed following unilateral enucleation even when the remaining eye and its surrounding tissues are covered by a firmly fitted rubber cup (approximately $16 \mathrm{~mm}$ in diameter). It may be that no system can totally prevent large differences in luminous flux from being visually detected by albino rats, because light can more easily transit unpigmented tissue.

During Experiment 1, the acrylic pedestal to which the cup appliance was affixed detached from several animals, paralleling the situation one commonly observes in animals with electrode implants: The animals "lose" their pedestals. This problem, coupled with the technical difficulties of fitting cup appliances and the finding that there are circumstances under which contact eye covers prevent discrimination of black-white cues, even after 300 trials, led us to concentrate on further evaluations of the effectiveness of the contact eye cover. 


\section{EXPERIMENT 2}

Experiment 2 was designed to assess the effects of differing conditions of visual restriction, as well as three types of contact eye covers, on rate of acquisition of a pattern discrimination by albino rats. The question of whether the mere wearing of a contact eye cover might influence an animal's performance was also addressed by training animals wearing transparent eye covers.

\section{Method}

Subjects. Subjects were 120 female albino rats of the Sprague-Dawley strain obtained from Charles River Laboratories, Wilmington, Massachusetts. They were approximately 80 days of age, and their body masses averaged about $250 \mathrm{~g}$. During the experiment the animals were housed four per cage and had free acess to food and water.

Apparatus. The animals were trained in a Thompson-Bryant apparatus somewhat larger than that used in Experiment 1a; its dimensions were those of the apparatus used by Levinson (1972) (Figure 4). Each of the two entryways led into the goal area through a $11.5 \times 11.5 \mathrm{~cm}$ opening in a plywood panel that segregated the entryway and goal areas. The entryway grids extended $15 \mathrm{~cm}$ into the runway area and were separated by a vertical partition of plywood $(30.5 \mathrm{~cm}$ high), the leading edge of which defined the choice point. The apparatus was covered by a transparent Plexiglas lid, and its interior was illuminated from above by a 10-W fluorescent lamp at approximately $25 \mathrm{~cm}$. The cue doors, each $12.7 \times 12.7 \mathrm{~cm}$, were constructed of $.6-\mathrm{cm}$ thick Plexiglas. The discriminanda consisted of $1.3-\mathrm{cm}$ alternating black and white stripes that oriented either horizontally or vertically. Motivational shock was provided by approximately $250 \mathrm{~mW}$ of power-stabilized, $60-\mathrm{Hz}$ ac pulsed (duty cycle: $.5 \mathrm{sec}$ on, $.5 \mathrm{sec}$ off) current from a Lehigh Valley Electronics sine-wave shocker, Model 1311.

Reversible monocular or binocular coverage was achieved by the use of either transparent, translucent (white), or opaque (black) contact eye covers that were prepared and applied as described earlier.

Procedure. Sixteen animals were randomly assigned to each of the following five training conditions: (1) no eye coverage (NN), (2) monocular transparent (clear) coverage (NC), (3) monocular translucent coverage (NT), (4) monocular opaque coverage (NO), or (5) unilateral enucleation (NE). Eight animals were similarly assigned to each of five other conditions: (1) opaque coverage of one eye plus clear coverage of the other eye (OC), (2) binocular clear coverage (CC), (3) binocular translucent coverage (TT), (4) binocular opaque coverage (OO), and (5) bilateral enucleation (EE). The animals that underwent enucleation were anesthetized with ether; enucleations were

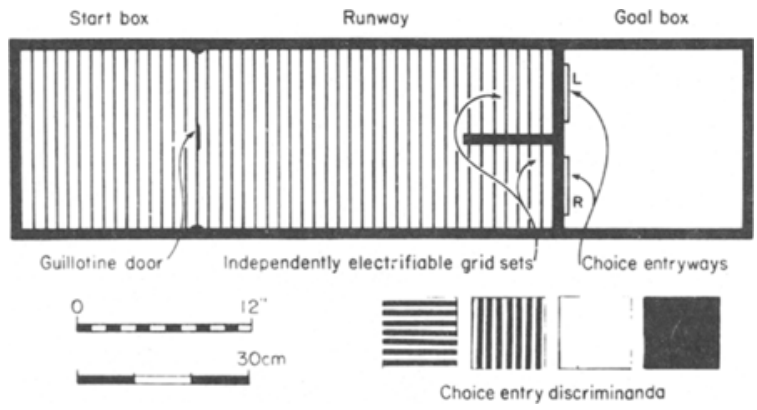

Figure 4. Schematic diagram of the Thompson-Bryant apparatus used in the series of experiments.
Table 2

Experiment 2: Mean and Median Trials to Criterion, Ranges, and Standard Deviations

\begin{tabular}{crrrr}
\hline Condition & Mean & Median & Range & SD \\
\hline NN & 76.88 & 76.5 & 79 & 19.42 \\
NC & 84.83 & 80.0 & 93 & 26.06 \\
NT & 123.31 & 103.0 & 218 & 62.76 \\
NO & 117.00 & 99.0 & 215 & 59.50 \\
NE & 90.56 & 75.0 & 215 & 49.11 \\
OC & 128.13 & 101.5 & 165 & 52.50 \\
CC & 144.88 & 104.0 & 199 & 83.18 \\
TT & 238.28 & 250.0 & 93 & 83.18 \\
OO & 250.00 & 250.0 & 0 & 00.00 \\
EE & 250.00 & 250.0 & 0 & 00.00 \\
\hline
\end{tabular}

Note $-N N=$ no eye coverage; $N C=$ monocular clear coverage, $N T=$ monocular translucent coverage; NO $=$ monocular opaque coverage; $N E=$ unilateral enucleation; $O C=$ opaque coverage of one eye plus clear coverage of the other eye; $C C=$ binocular clear coverage; $T T=$ binocular translucent coverage; $O O=$ binocular opaque coverage; $E E=$ binocular enucleation.

performed by grasping the eye of the anesthetized rat with forceps and cutting the orb away with iris scissors. Laterality of eye removal was counterbalanced among the 16 monocularly enucleated animals. All 24 enucleated animals were given 2-3 days to recover from the surgery.

The discriminative training procedure employed was similar to that used in Experiment 1a. After the animals had been pretrained to avoid the onset of shock, their eyes were covered according to preassigned treatment conditions and then they were given 25 trials/day until a criterion of 18 correct responses in 20 consecutive trials was met. If an animal did not achieve the criterion within 250 trials, its training was terminated.

\section{Results}

Means and medians of trials to criterion for each of the 10 groups of animals are presented in Table 2, as are ranges and standard deviations. The control animals (Group NN) reached criterion in an average of 76.88 trials.

Monocular coverage. An analysis of variance was performed on the data of monocularly treated Groups $\mathrm{NN}, \mathrm{NC}, \mathrm{NT}, \mathrm{NO}$, and NE; the analysis revealed a reliable difference $[F(4,75)=2.88, p<.05]$. In a series of comparisons by $t$ tests, it was found that the performance of Group NN did not differ reliably from that of Groups NC or NE [both $\operatorname{ts}(30)=1.00$, both ps> .20]. However, the animals in Group NN mastered the discrimination in reliably fewer trials than did either the animals in Group NT $[\mathrm{t}(30)=2.74, \mathrm{p}<.01]$ or those in Group NO $[\mathrm{t}(30)=2.48, \mathrm{p}<.02]$.

The rates of acquisition of the groups of animals that presumably obtained binocular input of cuing information (Groups NN and NC) were compared with those of groups of animals that presumably obtained only monocular input of the information (Groups NT, NO, and NE). The analysis revealed that the two sets of groups differed reliably $[t(78)=2.66, p<.01]$. The latter groups of animals required more trials to reach criterion; further, the distributions of Groups NT, NO, 
and NE showed increased skewness and variability as compared to the distributions of Groups NN and NC (see Table 2).

Binocular coverage. One of the animals in Group 00 removed one of its eye covers on Day 1 of discrimination training and therefore its data were excluded from the final analyses. None of the other seven animals wearing two opaque eye covers was able to reach criterional performance within 250 trials, and none of the eight binocularly enucleated animals, as expected, was able to master the discrimination. Due to the limitations imposed (by employment of the 250-trial cutoff point) on the homogeneity of variances of the distributions of the binocularly treated groups, the data of these animals were analyzed by nonparametric tests. Of the 16 animals that received input of cue information to at least one eye (Groups $\mathrm{CC}$ and $\mathrm{OC}$ ), 12 were able to master the discrimination. Although animals of Group $\mathrm{CC}$ required somewhat more trials on the average to reach criterion than did those of Group OC (144.87 vs. 128.12), the medians of the two groups were similar, and the groups did not differ reliably in terms of the number of animals reaching criterion ( $\mathrm{p}>.24$, Fisher's exact test).

Of the 23 animals that presumably received no input of visual information (Groups TT, OO, and EE), only one (in Group TT) was able to reach criterional performance within the 250 -trial limit. When the data of these animals were compared with the data of the animals in Groups CC and OC in terms of the number of rats mastering the task within 250 trials, the two sets of groups were found to differ reliably $\left[\chi^{2}(1)=21.14, p<.001\right]$. Because none of the animals in either Group $0 O$ or Group EE mastered the discriminative task within 250 trials, no statistical comparison between these groups was made.

\section{Discussion}

The findings with subjects wearing binocularly placed opaque eye covers differ strikingly from those of Chorover and Chase (1968). These animals did not differ reliably from those that were bilaterally enucleated, and neither group reached criterion within the 250-trial limit. Presumably, the greater diameter of our eye covers was responsible for the difference between the findings of Experiment 2 and those of Experiment 1a, as well as those of Chorover and Chase (1968).

The lack of a reliable difference between the control group (NN) and Group NC suggests that the mere wearing of one eye cover does not necessarily hinder an animal's ability to master a discriminative task, provided that the eye cover is transparent. If the eye cover is opaque or translucent, however, the animals are hindered in their efforts to learn the task and require more mean trials to criterion than do even their unilaterally enucleated counterparts. Since Groups NN and NE did not differ reliably on acquisition of the task, the inferior performances of Groups NO and NT would appear to be a result of monocular restriction of input coupled with the wearing of an eye cover. If monocular restriction of visual input were solely responsible for retarding performance on the task, one would not expect Groups NO and NT to differ from Group NE; that they do is puzzling. It is possible that the combination of one eye unhindered and one eye covered by an appliance (that partially or totally blocks input of information) leads to a greater degree of information distortion for the animals than does the combination of one eye open and one eye lost.

That Group CC required many more trials to reach criterion than did either Group NN or Group NC indicates that the animals wearing two clear eye covers suffered from loss of information, which may have stemmed from optical distortion of the acrylic when the eye covers were manufactured. The similarity of acquisition rates of Groups $\mathrm{CC}$ and $\mathrm{OC}$ suggests that for animals wearing two eye covers the effects of distortion are minimal when one of the eye covers is opaque, provided that the other is clear.

Since one of the animals in Group TT mastered the discrimination within 250 trials, the effectiveness of the translucent eye cover in restricting visual input is slightly suspect and its effectiveness would undoubtedly be even more suspect in the case of a brightness task. In contrast, none of the animals in Group 00 were able to learn the discriminative task, and in this regard their performances were identical to those of the animals in Group EE. These data suggest that the opaque eye cover is as effective as enucleation in restricting input of visual information.

It appears that, under some circumstances, contact eye covers are thoroughly effective in preventing discrimination of patterns. The problem is to identify the circumstances. Chorover and Chase (1968) trained their animals to discriminate prior to tests under binocular coverage. In Experiment 2, subjects were required to learn the pattern discrimination while binocularly covered, not just to retain it under such visual limitations.

\section{EXPERIMENT 3}

The data of Experiment 2 indicate that animals wearing two opaque eye covers perform as though totally blind in attempting to acquire a horizontalvertical discriminative habit. Experiment 3, like that of Chorover and Chase (1968), assayed the effects of binocular opaque coverage upon subsequent recognition of such a discriminative task following prior acquisition.

\section{Method}

Subjects. Subjects were four male albino rats of the SpragueDawley strain, weighing $350 \mathrm{~g}$ each and approximately 120 days old. 
Apparatus. The Thompson-Bryant apparatus used in Experiment 1a was employed.

Procedure. The animals were pretrained to avoid shock per procedure of Experiment 1a and were then trained to criterional performance $(18 / 20)$ on the horizontal-vertical task. After reaching criterion, two animals were given approximately 300 additional trials with both eyes covered; the other two animals were also given 300 additional trials in which binocular coverage alternated with unrestricted visual input over successive 12-trial blocks. [Each 12-trial block in the Fellows (1967) series contained an equal number of right and left choices.]

\section{Results and Discussion}

Percentages of correct responses at criterion and postcriterion are presented in Table 3 . The four animals met criterion in an average of 90 trials. The two animals that received 300 postcriterional trials with both eyes covered performed at an average of $49 \%$ and $43 \%$ correct; after 300 trials, they were still performing at chance levels (58\%). The two animals that received alternating series of trials under binocular coverage and no coverage also performed at chance levels (38\% and $43 \%$ correct, respectively) when both eyes were covered. However, with both eyes open they continued to respond at criterional levels (91\% and $90 \%$ ). Thus, the contact eye covers effectively blocked recognition of a pattern discrimination across 300 trials after prior acquisition, as well as under conditions when eye coverage was alternated with recognition tests (both eyes open), which in effect constituted overtraining on the task. These data, coupled with those of Experiment 2, imply that contact eye covers are effective restrictors of information relevant to the discrimination of patterns. Further, binocular coverage did not impair performance on subsequent tests with both eyes open (alternating condition).

\section{EXPERIMENT 4}

The findings of Experiments 2 and 3 indicate that contact eye covers are an effective means of blocking visual input, at least with regard to a pattern discrimination. Nonetheless, data from other studies have cast doubt upon their effectiveness. Although Sheridan and Shrout (1965) reported that binocular coverage reduced performance of a previously acquired pattern habit to chance levels, albino rats trained in a black-white discrmination performed above chance levels when given 20 test trials with both eyes covered. The ability of rats to perform a black-white discrimination while binocularly covered was also observed in Experiment 1. Sheridan and Shrout (1965) suggested that the above-chance performance was probably due to leakage of light around the edges of the contact eye cover. Subsequently, Chorover and Chase (1968) trained albino and hooded rats on a horizontal-vertical task in a Thompson-Bryant apparatus to a criterion of $17 / 20$ correct, and then gave them 180 to 200 additional training trials on the same task with both eyes fitted with contact eye covers. The hooded rats performed at chance levels; however, the albinos, following an initial impairment in performance, improved steadily until they had reached a criterional level of $90 \%$ correct. These findings seem to contradict those of Experiment 3, wherein the animals performed at chance levels after 300 postcriterional trials. The most probable sources of the differences in the two studies are the size of the contact eye covers, and the levels of light under which the animals were trained. Chorover and Chase used contact eye covers with a base diameter of $5.46 \pm .05 \mathrm{~mm}$ and a depth of $2.18 \pm .20 \mathrm{~mm}$; their stimulus intensity was $2.8 \mathrm{ftL}(.26 \mathrm{~lx})$. Our eye covers had a base diameter of approximately $7.0 \mathrm{~mm}$ and a depth of $3.5 \mathrm{~mm}$, although variations from these typical figures, as well as variations in sizes of the rats' eyes, might account for intermittent leakage. In Experiment 4, sizes of contact eye covers and light intensities were varied to assess their roles in contributing to the effectiveness of visual occlusion.

\section{Method}

Subjects. Nine male albino rats of the Sprague-Dawley strain served as subjects; body masses ranged from 300 to $350 \mathrm{~g}$.

Apparatus. The animals were trained on a brightness task in the Thompson-Bryant apparatus described in Experiment $1 \mathrm{~b}$. The contact eye covers were made from $.25-\mathrm{mm}$ black vinyl acrylic.

Procedure. Four days prior to training, the right eye of each animal was enucleated as described under Experiment 2. After surgical recovery, the animals were pretrained to avoid shock, and then were trained for 25 trials/day on the brightness task. Training was to a criterion of five or fewer errors in 25 trials ( $>80 \%$ correct) to be reached each day for 3 days. Since criterional performance was achieved on different days by various animals, all subjects were given 1 final day of training after reaching criterion (all animals responded correctly at least $80 \%$ of the time on the postcriterional measure).

Following completion of training, animals were tested for retention of the discrimination under different levels of

Table 3

Experiment 3: Percentage of Correct Responses at Criterion and Postcriterion (PC)

\begin{tabular}{|c|c|c|c|c|c|c|c|}
\hline \multirow[b]{2}{*}{ Subject } & \multirow[b]{2}{*}{ Criterion } & \multicolumn{2}{|c|}{ First 24 Trials PC } & \multicolumn{2}{|c|}{ Last 24 Trials $\mathrm{PC}$} & \multicolumn{2}{|c|}{ Overall PC Percentage } \\
\hline & & $\begin{array}{l}\text { Eyes } \\
\text { Open }\end{array}$ & $\begin{array}{c}\text { Eyes } \\
\text { Closed }\end{array}$ & $\begin{array}{l}\text { Eyes } \\
\text { Open }\end{array}$ & $\begin{array}{c}\text { Eyes } \\
\text { Closed }\end{array}$ & $\begin{array}{l}\text { Eyes } \\
\text { Open }\end{array}$ & $\begin{array}{l}\text { Eyes } \\
\text { Closed }\end{array}$ \\
\hline $\begin{array}{l}1 \\
2 \\
3 \\
4\end{array}$ & $\begin{array}{l}90 \\
90 \\
90 \\
90\end{array}$ & $\begin{array}{l}79 \\
79\end{array}$ & $\begin{array}{l}29 \\
33 \\
33 \\
42\end{array}$ & $\begin{array}{r}100 \\
83\end{array}$ & $\begin{array}{l}58 \\
42 \\
54 \\
58\end{array}$ & $\begin{array}{l}91 \\
90\end{array}$ & $\begin{array}{l}38 \\
43 \\
49 \\
43\end{array}$ \\
\hline
\end{tabular}


Table 4

Experiment 4: Size of Eye Covers (Millimeters)

\begin{tabular}{lcc}
\hline & Diameter & Height \\
\hline Small & $5.9 \pm .2$ & $2.2 \pm .2$ \\
Medium & $6.7 \pm .2$ & $3.0 \pm .2$ \\
Large & $7.2 \pm .2$ & $4.0 \pm .2$ \\
\hline
\end{tabular}

illumination and size of eye cover. These variables were incorporated into a 9 by 9 Latin square design, with each animal tested under the nine conditions (combination of three levels of light intensity with three sizes of eye cover). The dimensions of the eye covers are given in Table 4 . The levels of luminous flux at the discriminanda were $.01, .11$, and $.26 \mathrm{~lx}$, respectively, as measured by a General Electric Mode1 213 light meter. Each rat's remaining eye was covered and the animals were given 30 trials/day under each test condition until they had been tested for retention of the brightness discrimination under all nine conditions. Order of presentation of the various conditions was counterbalanced across subjects, and only random blocks of 30 trials were employed; left-right position of the correct cue was randomly but equally distributed.

\section{Results}

The mean number of errors made by the animals during the 30 -trial retention tests under each of the nine conditions is presented in Table 5 . The animals fitted with the smallest appliance performed better than chance (67\% correct). However, as the size of the eye cover increased, performance fell to chance levels; the animals wearing the largest eye covers performed correctly only $46 \%$ of the time. Analysis of variance revealed that the base diameter of the eye cover was reliably and inversely associated with the level of performance $[F(2,56)=31.52, p<.001]$. The varying light intensities had no effect on performance $[F(2,56)=.35, p>.35]$ regardless of the diameter of the eye cover with which they were combined [interaction $F(4,56)=.67, p>.35$ ] . Duncan's multiple range test revealed that the small eye covers were reliably less effective in impairing retention than were the medium size covers. These appliances in turn were reliably less effective than the large eye covers $(p<.01$; protection level $=98 \%$ ).

\section{Discussion}

The findings indicate that the size of the eye cover is a critical factor that determines the effectiveness of the appliance in blocking visual input. The smallest eye covers ( $5.9 \pm .2 \mathrm{~mm}$ base diameter) were larger than those employed by Chorover and Chase (1968), and yet they were still ineffective in reducing performance to chance levels. Chance levels were not attained until the base diameter of the eye cover was at least $6.7 \mathrm{~mm}$. In discussing the ineffectiveness of their appliances in restricting visual input, Chorover and Chase mentioned that, based on the data of Lashley (1932), the cornea of the rat's eye has a base diameter of approximately $6 \mathrm{~mm}$. Thus, to restrict visual input effectively, an eye cover for the rat should have a minimal base diameter approximating $6 \mathrm{~mm}$. The smallest eye covers used in our studies and by Chorover and Chase had base diameters smaller than $6 \mathrm{~mm}$; they were ineffective in reducing performance to, or maintaining it at chance levels. Conversely, the intermediate $(6.7-\mathrm{mm})$ and largest (7.2- $\mathrm{mm})$ eye covers reduced performance to chance levels (54\% and $46 \%$, respectively). These data indicate that an eye cover midway between the medium- and large-sized covers used in Experiment 4 probably is effective in blocking visual input, at least for recognition of patterns. Although the difference between the eye covers used by Chorover and Chase (1968) and those used by us in our studies of interocular transfer is small (roughly a $1.5-\mathrm{mm}$ difference in diameter), the difference appears to be critical.

\section{EXPERIMENT 5}

Chorover and Chase (1968) also tested the effectiveness of eye covers by electrophysiological means and reported that, although the eye cover markedly attenuated the visually evoked response (VER) in hooded rats, no such attenuation was obtained in the albino. These findings were in concert with behavioral data and suggested that such measures would be of value in determining the effectiveness of our contact eye covers. Electrophysiological assessment (see Creel, 1971; Creel, Dustman, \& Beck, 1970) was therefore performed on the three eye covers studied behaviorally in Experiment 4.

\section{Method}

Subjects. Five of the monocularly enucleated albino rats used in Experiment 4 participated as subjects.

Apparatus and Procedure. Each animal was anesthetized intraperitoneally with sodium pentobarbital $(35 \mathrm{mg} / \mathrm{kg})$ and was then placed in a stereotaxic instrument. A cortical electrode-a small, stainless-steel calvarium screw-was implanted to contact the dura over primary visual cortex contralateral to the remaining eye; contact was made $4 \mathrm{~mm}$ lateral to the sagittal suture and $3 \mathrm{~mm}$ anterior to the lambdal suture. A reference electrode was implanted on the midline $9 \mathrm{~mm}$ anterior to the bregmal suture. Each electrode had a contact area of approximately $1.5 \mathrm{~m}^{2}$. The electrode's leads, formed from

Table 5

Experiment 4: Mean Number of Errors in 30-Trial Retention Test

\begin{tabular}{lrrrrrrrrr}
\hline & \multicolumn{8}{c}{ Size of Eye Cover } \\
\cline { 2 - 9 } & \multicolumn{1}{c}{ Small } & \multicolumn{1}{c}{ Medium } & \multicolumn{1}{c}{ Large } \\
\hline Light Intensity (1x) & .01 & .11 & .26 & .01 & .11 & .26 & .01 & .11 & .26 \\
Mean Errors & 11.22 & 9.78 & 9.89 & 14.44 & 14.55 & 12.11 & 16.00 & 16.11 & 16.78 \\
Overall Mean Errors & & 10.79 & & & 14.03 & & & 16.30 & \\
\hline
\end{tabular}




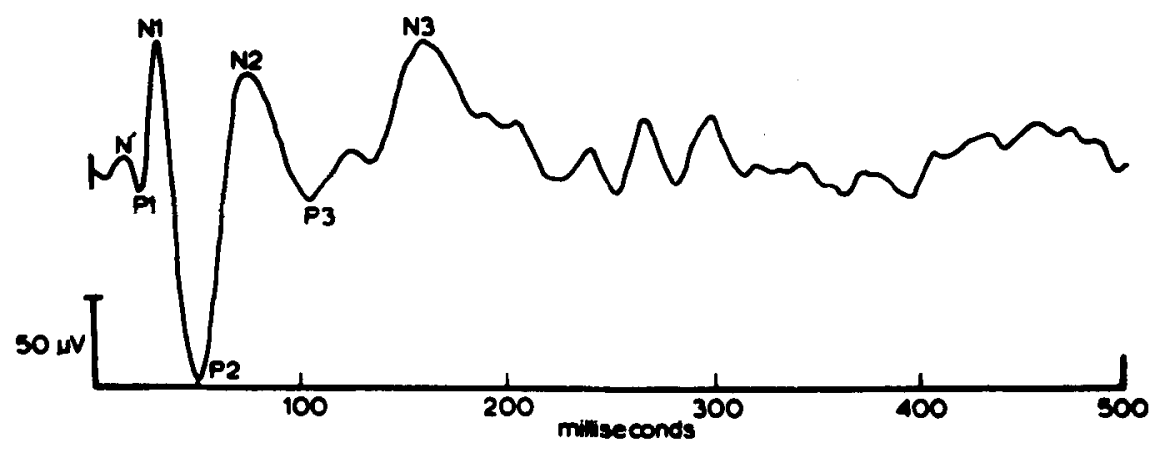

Figure 5. Typical VER obtained from a rat. Negative is up.

$5-\mathrm{mm}$ lengths of enameled nichrome wire, were presoldered at one end to a cortical screw and at the other to the pins of a miniature Cannon plug. The Cannon plug served as a connecting pedestal and was secured to the calvarium with dental acrylic. The animals were allowed a week to recover from surgery.

During recording of VERs, each animal was placed in a white plastic cylinder $20 \mathrm{~cm}$ in diameter and was allowed to move about freely. A long lead connected the animal's pedestal (and, in turn, its cortical electrodes) to an electrode board of a Grass Model 6-8-2 EEG polygraph. The ambient light in the laboratory was provided by a red, $25-\mathrm{W}$ incandescent lamp. At the beginning of recording sessions, several drops of $2 \%$ isoptohomatropine were applied to the cornea to control pupillary motility. Electrical activity as evoked by a Grass Model PS2C photic stimulator set at PS4 $(20 \mathrm{~lx})$ was recorded from the visual cortex. The lamp of the Grass photic stimulator was located $30 \mathrm{~cm}$ above the animal's head and produced a flash of light of 10-microsec duration (the lamp was enclosed in a polyethylene cylinder and was surrounded by a soft plastic foam that attenuated clicking noise from the xenon bulb). The output of the Grass polygraph was coupled to a Fabri-Tek Model 1052-LSH signal averager. The averager was programmed to record and to sum time-locked potentials for $500 \mathrm{msec}$ at presentation of each photic stimulus. Ink records of summed series of evoked responses were then read out on a HewlettPackard X-Y plotter.

The VERs were recorded from the animals under four conditions: no eye coverage, or coverage of the eye with one of the three eye covers of differing diameter. Order of presentation of the four conditions of eye coverage was counterbalanced across animals. While responses were recorded under each condition of eye coverage, photic stimuli were presented in blocks of 50 flashes, with individual flashes recurring at approximately 3 -sec intervals. The responses to each block of 50 flashes were summed and compared on the basis of peak-topeak amplitudes for the first negative-positive (N1-P2) component. A typical VER is presented in Figure 5.

\section{Results and Discussion}

Individual and mean values of peak-to-peak voltages, and standard errors, are presented in Table 6. Coverage of the eye with the smallest appliance resulted in virtually no attenuation of the N1-P2 component. However, as the size of the eye cover increased, the attenuation was sizable; the largest eye cover led to a 50\% attenuation of the VER. These data are histographically presented in Figure 6 . An analysis of variance showed increased attenuation resulting from the increasing size of eye cover was reliable $[F(3,12)=6.12$, $\mathrm{p}<.01]$; individual differences between subjects were also found to be reliable $[F(4,12)=4.94, p<.05]$.
Complete attenuation of the VER was not obtained even with the largest of the eye covers. It may be that in order to obtain total attenuation, one must cover the eyes-and perhaps the entire head-with opaque electrical tape, as did Chorover and Chase (1968).

The magnitude of reduction of the N1-P2 component of the VER (approximately 50\%) obtained with the largest eye cover $(7.2 \mathrm{~mm})$ in the albino rat is comparable to the reduction in the VER obtained by Chorover and Chase (1968) in the hooded rat. Their eye covers were 5.62 and $5.73 \mathrm{~mm}$ in base diameter (a little larger than those used in their behavioral assessments), but still smaller than our smallest eye cover $(5.9 \mathrm{~mm})$. Chorover and Chase did not obtain attenuation of the VER in the albino rat, except when eyes were covered with electrical tape. So, too, with our smallest eye cover: no attenuation of the VER in the albino rat occurred. Size of the eye cover is a critical factor in determining its effectiveness. An eye cover 5.6 to $5.7 \mathrm{~mm}$ in base diameter seems sufficiently large to restrict visual input in hooded rats (see Chorover $\&$ Chase, 1968); however, with albinos one must employ an eye cover that approaches the size of the largest $(7.2 \mathrm{~mm})$ used in our experiments. The resulting attenuation of the VER is then similar to that obtained in the hooded rat with an eye cover of the size employed by Chorover and Chase (1968).

\section{GENERAL DISCUSSION}

Our studies were performed to determine the effectiveness of contact eye covers as a means of

Table 6

Experiment 5: Individual and Mean Peak-to-Peak Microvoltages, and Standard Errors, Under Various Conditions of Eye Coverage

\begin{tabular}{lrrrr}
\hline & \multicolumn{4}{c}{ Eye Coverage } \\
\cline { 2 - 5 } Subject & \multicolumn{1}{c}{ None } & \multicolumn{1}{c}{ Small } & Medium & Large \\
\hline 1 & 125.26 & 165.62 & 133.01 & 72.66 \\
2 & 58.38 & 71.49 & 34.15 & 48.52 \\
3 & 104.22 & 122.35 & 73.83 & 21.66 \\
4 & 131.35 & 69.38 & 60.09 & 56.96 \\
5 & 103.30 & 85.58 & 76.62 & 56.22 \\
Mean & 104.50 & 102.88 & 75.54 & 51.00 \\
SE & 12.83 & 18.38 & 16.25 & 8.25 \\
\hline
\end{tabular}




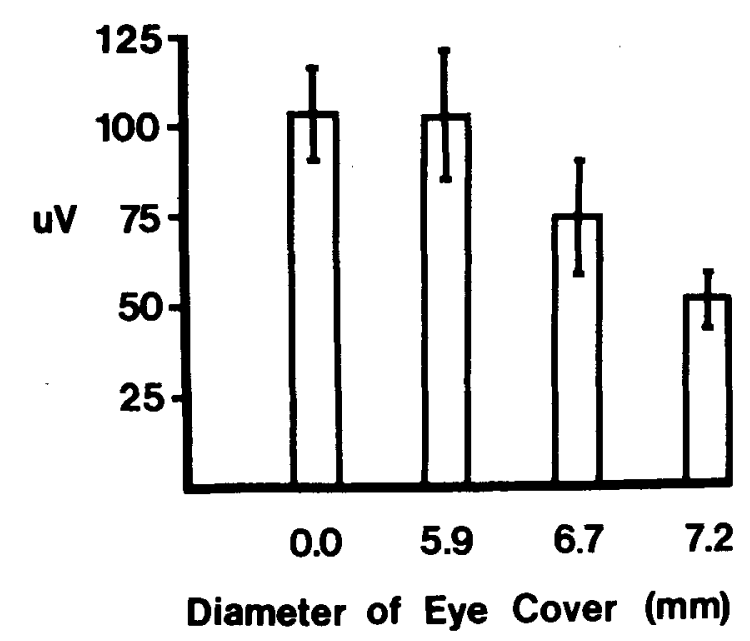

Figure 6. Histogram of mean peak-to-peak microvoltages for the N1-P2 component of the VER, and standard errors.

restricting visual input in the rat and to delineate some of the critical parameters underlying the degree of effectiveness of such eye covers. Appliances normally used to restrict visual input in human, monkey, or cat subjects (e.g., blindfolds or eye patches) will not work with rats or with other rodents for a variety of reasons. Alternative methods are required. The most logical candidate appeared to be small floating contact lenses similar to those described by Shuck and Copolla (1963); yet, in several studies the effectiveness of these "occluders" was questionable (e.g., Chorover \& Chase, 1968; Sheridan \& Shrout, 1965). The findings of these studies indicates that estimates of interocular transfer from earlier studies may have been inflated due to leakage of information through the covered eye.

In Experiment 1, the contact eye cover was compared with an implantable rubber cup appliance. The technique is effective in blocking visual input in some situations, but not in others. However, the contact eye cover was as effective as the cup appliance. Since the rubber cup requires surgery, which may in turn preclude other surgical procedures, and since the pedestal may become detached, it was abandoned as a viable technique for achieving reversible blindness. In Experiment 2, monocular and binocular contact eye coverage, as well as the effectiveness of transparent, translucent, and opaque appliances, were compared. Binocular coverage with opaque eye covers was as effective as binocular enucleation in blocking acquisition of a horizontal-vertical discrimination; that is, animals wearing two opaque eye covers performed as if blind. Monocular coverage retarded acquisition somewhat as compared to no eye coverage; such retardation, however, would not be a factor in studies on interocular transfer or related areas, since in these studies both experimental and control subjects are trained and tested while wearing one opaque eye cover. Experiment 3 demonstrated that binocular coverage is also completely effective in blocking recognition of a previously acquired (90 trials) pattern discrimination even after 300 postacquisition trials. With alternating conditions of binocular coverage and no coverage, no retention was observed when the animals were wearing two opaque eye covers, although successful performance occurred with no coverage. In Experiment 4 , the base diameter of the contact eye cover was perhaps the most critical factor influencing effectiveness in blocking visual input. In comparing eye covers of varying base diameters, it was found that the appliance had to be more than $5.9 \mathrm{~mm}$ in diameter, so as to reduce to chance levels performance of a previously acquired brightness discrimination. Such levels were achieved using appliances $6.7 \mathrm{~mm}$ and $7.2 \mathrm{~mm}$ in diameter. Chorover and Chase's (1968) observation of performances at better than chance levels by their albino rats appears to have resulted from the small diameter of their contact eye covers $(5.46 \mathrm{~mm})$.

Experiment 5 consisted of electrophysiological assessment of three contact eye covers of differing diameter. For the albino rat, one must use an appliance approaching $7.2 \mathrm{~mm}$ in diameter in order to obtain a degree of attenuation of the VER that is comparable to that obtained by Chorover and Chase (1968) in the hooded rat using an appliance $5.7 \mathrm{~mm}$ in diameter. The attenuation $>50 \%$ ) obtained in the albino rats in Experiment 5 with an eye cover $7.2 \mathrm{~mm}$ in diameter was reliable. These data further stress the importance of the size of the eye cover as a factor determining its effectiveness.

The results of all five studies suggest that the contact eye cover can be used to achieve reversible blindness. The cover can restrict acquisition of discriminative habits and can block performance of a previously acquired discrimination. These data imply that the cover is an effective occluder of visual input and therefore the term contact occluder seems justified. It appears that the data obtained in earlier studies on interocular transfer and related phenomena are valid, since the contact occluders used in these studies were of sufficient size $(7.0 \pm .2 \mathrm{~mm}$ in base diameter) to restrict visual input. Investigators who wish to utilize the contact occluder should observe several precautions: (1) For use with the albino rat $(300-500 \mathrm{~g})$, and probably hooded rats as well, the occluders must be at least $7.0 \mathrm{~mm}$ in diameter. (2) For use with guinea pigs $(500-700 \mathrm{~g})$, they should be $9.0 \mathrm{~mm}$ in diameter; although guinea pigs were not assessed in our studies, effective visual occlusion of the animal has been reported (Levinson, 1972; Levinson et al., 1977). (3) The occluder should be constructed of black (opaque) vinyl acrylic at least $.25 \mathrm{~mm}$ thick. If the rats or guinea pigs to be used have darkly pigmented eyes, opaque contact occluders should nonetheless be employed, as translucent occluders are not as effective. The outside surface of the occluder should 
be marked with a contrasting paint; by doing so, one can be sure that the animal has not lost its occluder during training and testing. Such loss is obvious with albino animals wearing black occluders, but not necessarily with ocularly pigmented animals wearing black occluders. The lack of contrast between the black eyes of certain pigmented animals and the opaque occluder necessitates painting the appliance with a contrasting paint. The leakage reported by Lynch and Sheridan (1970) in their pigmented guinea pigs is probably a result of their using black occluders that were not painted a contrasting color. The occluders may not have covered the eye to its base, or they may have slipped downward during the test trials. Such occurrences would not necessarily be noted, and thus the animals might not have really been binocularly occluded when tested. (4) The inner and outer surfaces of the occluders must be smooth and free of any abrasive agents that could cause damage to the eye or surrounding tissues. (5) The occluders can apparently be worn by an animal for 2-h durations without difficulty; however, they should never be left in place overnight or serious clouding of the eye can result (Shuck \& Coppola, 1963). (6) A wetting solution should be used before the occluder is fitted to the eye. And, (7) several animals should be tested over at least 20 trials with both eyes covered. Under conditions of binocular occlusion, performance by the animals should be at chance levels.

\section{REFERENCES}

Bergum, B. O., \& Flamm, L. E. Perceptual stability, image size, binocularity and creativity. Perceptual and Motor Skills, 1975, 41, 667-671.

Boles, T. J., \& Sheridan, C. L. Enhanced pattern discrimination learning following unilateral damage to posterior cortex in rats. Psychonomic Science, 1969, 16, 273-274.

Cheney, C. D., \& TAM, V. Interocular transfer of a line tilt discrimination without mirror-image reversal using fading in pigeons. Journal of Biological Psychology, 1972, 14, 17-20.

Chorover, S. L., \& Chase, R. Persistence of visual pattern discrimination in binocularly-occluded albino rats. Journal of Comparative and Physiological Psychology, 1968, 65, 238-245.

Corballis, M. C., \& Luther, L. Perception of lateral movement by monocularly viewing pigeons. Perception \& Psychophysics, 1973, 14, 41.44.

Cornwell, A. C. Electroretinographic responses following monocular visual deprivation in kittens. Vision Research, 1974, 14, 1223-1227.

CREEL, D. J. Differences of ipsilateral and contralateral visually evoked responses in the cat: Strains compared. Journal of Comparative and Physiological Psychology, 1971, 77, 161-165.

Creel, D. J., Dustman, R. E., \& Beck, E. C. Differences in visually evoked responses in albino versus hooded rats. Experimental Neurology, 1970, 29, 298-309.

Creel, D. J., \& Sheridan, C. L. Monocular acquisition and interocular transfer in albino rats with unilateral striate ablations. Psychonomic Science, 1966, 6, 89-90.
Fellows, B. J. Chance discrimination sequences for discrimination tasks. Psychological Bulletin, 1967, 67, 87-92.

Gibson, W. Dunninger's secrets. Secaucus, N.J: Lyle Stuart, 1974.

Herman, J. H., Tauber, E. S., \& Roffwarg, H. P. Monocular occlusion impairs stereoscopic acuity, but total vision deprivation does not. Perception \& Psychophysics, 1974, 16. 225-228.

HoRn, G., Rose, S. P. R., \& Bateson, P. P. G. Monocular imprinting and regional incorporation of tritiated uracil into the brain of intact and "split-brain" chicks. Brain Research, 1973, 56, 227-237.

HRANChUK, K. B., \& WEBSTER, W. G. Interocular transfer of lateral mirror-image discriminations by cats: Evidence of species differences. Journal of Comparative and Physiological Psychology, 1975, 88, 368-372.

LASHLEY, K. S. The mechanism of vision: V. The structure and image forming power of the rat's eye. Journal of Comparative Psychology, 1932, 13, 173-200.

Levinson, D. M. Interocular transfer in guinea pigs following section of the corpus callosum. Journal of Comparative and Physiological Psychology, 1972, 78, 26-31.

Levinson, D. M., Hottman, T. J., \& Sheridan, C. L. Assessment of the generality of enhanced learning following lesions of posterior neocortex in rats. Psychonomic Science, 1971, 22, 1-3.

Levinson, D. M., Riffle, D. W., Reeves, D. L., \& Sheridan, C. L. Enhancement of discrimination learning following unilateral lesions of posterior neocortex in guinea pigs. Physiology and Behavior, 1977, 19, 513-517.

Levinson, D. M., \& Sheridan, C. L. Acquisition and retention of monocular discriminations in rats as a function of relevant (reversal) or irrelevant opposite-eye training. Psychonomic Science, 1967, 8, 475-476. (a)

Levinson, D. M., \& Sheridan, C. L. Retention in guinea pigs of monocular pattern discriminations during reversal acquisition with the opposite eye. Psychonomic Science, $1967,7,239.240$. (b)

Levinson, D. M., \& Sheridan, C. L. Monocular acquisition and interocular transfer of two types of pattern discriminations in hooded rats. Journal of Comparative and Physiological Psychology, 1969, 67, 468-472.

LyNCh, K. A. B., \& SHERDAN, C. L. Interocular transfer of a brightness and of a pattern discrimination in albino and pigmented guinea pigs. Psychonomic Science, 1970, 20, 277-279.

Muntz, W. R. Z., \& Sutherland, N. S. The role of crossed and uncrossed optic nerve fibers in the visual discrimination of shape by rats. Journal of Comparative Neurology, 1964, 122, 69-77.

MYeRs, R. E. Interocular transfer of pattern discriminations in cats following section of crossed optic fibers. Journal of Comparative and Physiological Psychology, 1955, 48, 470.473.

Petre, C. C., \& Sheridan, C. L. Interocular transfer in albino and pigmented perinatal guinea pigs. Psychonomic Science, 1966, 6, 215-216.

Procopis. P. G., \& Jameson, H. D. The photoconvulsive response. Archives of Neurology, 1974, 31, 31-34.

Riffle, D. W., Reeves, D. L., \& Levinson, D. M. Monocular acquisition and interocular transfer in albino guinea pigs as mediated by ipsi- or contralateral fiber systems. Perceptual and Motor Skills, 1976, 42, 181-182.

SHERIdan, C. L. Interocular transfer of brightness and pattern discriminations in normal and corpus callosum-sectioned rats. Journal of Comparative and Physiological Psychology, 1965, 59, 292-294.

ShERIdan, C. L., \& Shrout, L. L. Interocular transfer in the rat: The role of the occlusion process. Psychonomic 
Science, 1965, 2, 173-174.

Sheridan, C. L., \& Shrout, L. L. Differences in the effectiveness of the optic uncrossed fiber systems in albino and hooded rats. Psychonomic Science, 1966, 4, 177.178.

Shuck, J. R., \& Coppol.A, L. A. Contact occluders for restricting vision in the rat. American Joumal of Psychology, $1963,76,135-137$.

SPERRY, R. W. Cerebral organization and behavior. Science, 1961, 133, 1749-1757.

Thompson, R., \& BRYANT, H. Memory as affected by activity of the relevant receptor. Psychological Reports, 1955, 1, $393-400$.

Tieman, S. B., Tieman, D. G., Brady, B. A., \& Hamilton,
C. R. Interocular reversal of up-down mirror images in pigeons. Physiology and Behavior, 1974, 12, 615.620.

van Hof, M. W., \& Lagers-van Haselen, G. C. Monocular pattern discrimination in rabbits after unilateral ablation of the visual cortex. Experimental Neurology, 1975, 46, 257.259.

Zubek, J. P., \& Bross, M. Depression and later enhancement of the critical flicker frequency during prolonged monocular deprivation. Science, 1972, 176, 1045-1047.

(Received for publication July 5, 1977; revision accepted November 30,1977 .) 